\title{
Corrosion Inhibition and Adsorption Behavior of Clove Oil on Iron in Acidic Medium
}

\author{
ARCHANA SAXENA*1, ANURAG SHARMA ${ }^{1}$, DEEPTI SAXENA ${ }^{2}$, AND PRAVEEN \\ $\mathrm{JAIN}^{3}$ \\ ${ }^{1}$ Department of Chemistry, Swami Keshwanand Institute of Technology, M\&G Jaipur [Raj.] \\ 302025, India \\ ${ }^{2}$ Department of Chemistry, GGSS, New Delhi, India \\ ${ }^{3}$ Department of Physics, Swami Keshwanand Institute of Technology, M\&G Jaipur [Raj.] \\ 302025, India \\ draschem@gmail.com
}

Received 11 October 2011; Accepted 30 December 2011

\begin{abstract}
Corrosion behavior of iron in hydrochloric acid solution was studied using weight loss as well Scanning electron microscopy study without and with clove oil. The percentage inhibition efficiency increases with increasing clove oil concentration. All the data revel that the oil acts as an excellent inhibitor for the corrosion of iron in $\mathrm{HCl}$ solution. Thermodynamic ,kinetic parameters and equilibrium constant for adsorption process were calculated from the experimental data .The adsorption of clove oil on experimental metals was found to follow the Langmuir adsorption isotherm at all the concentration studies . Scanning electron microscope (SEM), investigations also indicate that clove oil greatly lowers the dissolution currents.
\end{abstract}

Keyword: Corrosion, Scanning electron microscope (SEM), Clove oil, Langmuir adsorption isotherm, Kinetics parameters.

\section{Introduction}

The corrosion inhibition efficiency has been closely related to the inhibitor adsorption abilities and the molecular properties of different kinds of organic compounds [1-5]. The power of the inhibition depends on the molecular structure of the inhibitor. Organic compounds, containing functional electronegative groups and p-electron in triple or conjugated double bonds, are usually good inhibitors. Heteroatoms, such as sulfur, phosphorus, nitrogen, and oxygen, together with aromatic rings in their structure are the major adsorption centers. The planarity and the lone electron pairs in the heteroatoms are important features that determine the adsorption of molecules on the metallic surface [6-7]. The molecules of clove oil have oxygen as active center. They are healthy and reportedly very important in biological reactions (i.e., not hazardous and environment friendly), and they can be easily produced and purified.

This aroused the interest of authors to select the clove oil as a corrosion inhibitor for iron in acidic medium. 
Cloves are the aromatic dried flower buds of a tree Eugenia caryophyllata in the family Myrtaceae found in India and other parts in the far East. Steam distillation of freshly ground cloves results in clove oil which consists of several compounds.Eugenol is the main compound comprising $85-90 \%$. Eugenol acetate comprises $9-10 \%$.

Eugenol is a member of the allyl benzene class of chemical compounds. It is a clear to pale yellow oily liquid It is slightly soluble in water and soluble in organic solvents. It has a pleasant, spicy, clove-like odour used as a spice in cuisine all over the world. It has pronounced antiseptic and anaesthetic properties. Eugenol is used in perfumeries, flavorings, essential oils and in medicine as a local antiseptic and anaesthetic.

Structure and formula of Eugenol is as follows.
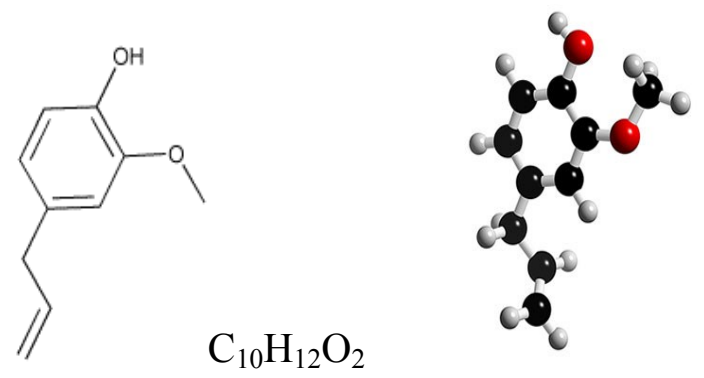

\section{Experimental}

Rectangular iron specimens with size $3 \times 2 \times 0.2 \mathrm{~cm}$. were used for weight loss method. These strips were given mechanical polishing with fine emery paper and degreased with acetone before use. After washing, the strips were dried in oven at $60^{\circ} \mathrm{C}$ for about half an hour and kept in desiccators for cooling to room temperature and weighed accurately using a digital balance. The strips were subjected to further heating, cooling and weighing till a constant weight was obtained and then stored in desiccators before use. The acidic solution was prepared with distilled water. One coupon was tested for its corrosion (weight loss) in acidic solution and other coupons were tested for inhibition of corrosion by clove oil in presence of different amounts of clove oils ( $1 \mathrm{~g}-5 \mathrm{~g} / \mathrm{lit})$ in acidic medium. The coupons were immersed by a glass hook in the beakers containing $50 \mathrm{ml} 0.5 \mathrm{~N} \mathrm{HCl}$ solution and different concentration ( $1 \mathrm{~g}-5 \mathrm{~g} / \mathrm{lit})$ of clove oils at room temperature (298K). After 1-5 days the test coupons were removed from the test solutions, cleaned with distilled water, dried in oven and weighed to evaluate weight loss.

The corrosion rate: It was calculated by using the following equation [8-9].

$$
\text { Corrosion rate }=(\mathrm{mm} / \mathrm{yr})=87.6 \mathrm{~W} / \mathrm{dAt}
$$

Where $\mathrm{W}$ is the weight loss $(\mathrm{mg}), \mathrm{d}$ is the density of the specimen $\left(\mathrm{gcm}^{-3}\right)$, A the area of specimen (square $\mathrm{cm}$ ) and the exposure time (h).

The percentage inhibition efficiency: It was calculated using following formula.

$$
\mathrm{IE} \%=\left[1-\mathrm{W}_{1} / \mathrm{W}_{2}\right] \times 100
$$

Where $\mathrm{W}_{1}$ and $\mathrm{W}_{2}$ are the weight losses ( $\mathrm{g}$ ) for iron in the presence and absence of clove oil respectively in $\mathrm{HCl}$ solution.

The degree of surface coverage $(\theta)$ : is given by the equation [10].

$$
\theta=1-\mathrm{W}_{1} / \mathrm{W}_{2}
$$




\section{Results and Discussion}

Effect of inhibitor concentration on iron corrosion by weight loss method:

Tables (1-5) show the values of inhibition efficiency (IE \%), surface coverage $(\theta)$ and corrosion rate obtained at different concentrations of the inhibitor in $0.5 \mathrm{~N} \mathrm{HCl}$ for 1 to 5 days immersion period. From the weight loss value, the inhibition efficiency (IE\%) and surface coverage $(\theta)$ were calculated. It is clear from observed data that the addition of inhibitor to the acid has reduced the corrosion rate.

Table 1. Inhibiton efficiency (\%IE), corrosion rate and surface coverage (at room temperature) obtained from weight loss method for iron in $0.5 \mathrm{~N} \mathrm{HCl}$ (Immersion time: 1 day).

\begin{tabular}{|l|l|l|l|l|}
\hline $\begin{array}{l}\text { Conc. of inhibitor } \\
(\mathbf{g} / \text { lit) }\end{array}$ & $\mathbf{W}(\mathbf{g})$ & $\mathbf{\% I E}$ & $\begin{array}{l}\text { Corrosion rate } \\
(\mathbf{m m p y})\end{array}$ & $\begin{array}{l}\text { Surface coverage } \\
(\boldsymbol{\theta})\end{array}$ \\
\hline- & 0.0163 & - & 12.97 & - \\
\hline 1 & 0.0038 & 76.68 & 3.02 & 0.7668 \\
\hline 2 & 0.0032 & 80.36 & 2.54 & 0.8036 \\
\hline 3 & 0.0025 & 84.66 & 1.99 & 0.8466 \\
\hline 4 & 0.0020 & 87.33 & 1.59 & 0.8733 \\
\hline 5 & 0.0015 & 90.79 & 1.19 & 0.9079 \\
\hline 6 & 0.0014 & 91.41 & 1.11 & 0.9141 \\
\hline
\end{tabular}

Table 2. Inhibiton efficiency (\%IE), corrosion rate and surface coverage (at room temperature) obtained from weight loss method for iron in $0.5 \mathrm{~N} \mathrm{HCl}$ (Immersion time: 2 days).

\begin{tabular}{|c|c|c|c|c|}
\hline $\begin{array}{c}\text { Conc. of inhibitor } \\
(\mathbf{g} / \text { /lit) }\end{array}$ & $\Delta \mathbf{W}(\mathbf{g})$ & $\mathbf{\% I E}$ & $\begin{array}{c}\text { Corrosion rate } \\
(\mathbf{m m p y})\end{array}$ & $\begin{array}{c}\text { Surface coverage } \\
(\boldsymbol{\theta})\end{array}$ \\
\hline- & 0.0183 & - & 4.85 & - \\
\hline 1 & 0.0070 & 61.74 & 1.85 & 0.6174 \\
\hline 2 & 0.0050 & 72.67 & 1.32 & 0.7267 \\
\hline 3 & 0.0037 & 79.78 & 0.98 & 0.7978 \\
\hline 4 & 0.0035 & 80.87 & 0.92 & 0.8087 \\
\hline 5 & 0.0030 & 83.60 & 0.79 & 0.8360 \\
\hline 6 & 0.0022 & 87.79 & 0.58 & 0.8779 \\
\hline
\end{tabular}

Table 3. Inhibiton efficiency (\%IE), corrosion rate and surface coverage (at room temperature) obtained from weight loss method for iron in $0.5 \mathrm{~N} \mathrm{HCl}$ (Immersion time: 3 days).

\begin{tabular}{|c|c|c|c|c|}
\hline $\begin{array}{c}\text { Conc. of inhibitor } \\
(\mathbf{g} / \text { lit) }\end{array}$ & $\Delta \mathbf{W}(\mathbf{g})$ & \%IE & $\begin{array}{c}\text { Corrosion rate } \\
(\mathbf{m m p y})\end{array}$ & $\begin{array}{c}\text { Surface coverage } \\
(\boldsymbol{\theta})\end{array}$ \\
\hline- & 0.0215 & - & 2.85 & - \\
\hline 1 & 0.0075 & 65.11 & 0.99 & 0.6511 \\
\hline 2 & 0.0073 & 66.04 & 0.96 & 0.6604 \\
\hline 3 & 0.0065 & 69.79 & 0.86 & 0.6979 \\
\hline 4 & 0.0050 & 76.74 & 0.66 & 0.7674 \\
\hline 5 & 0.0040 & 81.39 & 0.53 & 0.8139 \\
\hline 6 & 0.0028 & 86.97 & 0.37 & 0.8697 \\
\hline
\end{tabular}


Table 4. Inhibiton efficiency (\%IE), corrosion rate and surface coverage (at room temperature) obtained from weight loss method for iron in $0.5 \mathrm{~N} \mathrm{HCl}$ (Immersion time: 4 days).

\begin{tabular}{|c|c|c|c|c|}
\hline $\begin{array}{c}\text { Conc. of inhibitor } \\
(\mathbf{g} / \text { lit) }\end{array}$ & $\Delta \mathbf{W}(\mathbf{g})$ & $\mathbf{\% I E}$ & $\begin{array}{c}\text { Corrosion rate } \\
(\mathbf{m m p y})\end{array}$ & $\begin{array}{c}\text { Surface coverage } \\
(\boldsymbol{\theta})\end{array}$ \\
\hline- & 0.0315 & - & 1.67 & \\
\hline 1 & 0.0125 & 60.31 & 0.66 & 0.6031 \\
\hline 2 & 0.0115 & 63.49 & 0.61 & 0.6349 \\
\hline 3 & 0.0101 & 67.93 & 0.53 & 0.6793 \\
\hline 4 & 0.0097 & 69.20 & 0.51 & 0.6920 \\
\hline 5 & 0.0091 & 71.11 & 0.48 & 0.7111 \\
\hline 6 & 0.0087 & 73.38 & 0.46 & 0.7338 \\
\hline
\end{tabular}

Table 5. Inhibiton efficiency (\%IE), corrosion rate and surface coverage (at room temperature) obtained from weight loss method for iron in $0.5 \mathrm{~N} \mathrm{HCl}$ (Immersion time: 5 days).

\begin{tabular}{|c|c|c|c|c|}
\hline $\begin{array}{c}\text { Conc. of inhibitor } \\
(\mathbf{g} / \text { lit })\end{array}$ & $\Delta \mathbf{W}(\mathbf{g})$ & \%IE & $\begin{array}{c}\text { Corrosion rate } \\
(\mathbf{m m p y})\end{array}$ & $\begin{array}{c}\text { Surface coverage } \\
(\boldsymbol{\theta})\end{array}$ \\
\hline- & 0.0502 & - & 1.66 & 0.5617 \\
\hline 1 & 0.0220 & 56.17 & 0.72 & 0.6055 \\
\hline 2 & 0.0198 & 60.55 & 0.65 & 0.6264 \\
\hline 3 & 0.0187 & 62.64 & 0.62 & 0.6454 \\
\hline 4 & 0.0178 & 64.54 & 0.59 & 0.6673 \\
\hline 5 & 0.0168 & 66.73 & 0.55 & 0.6832 \\
\hline 6 & 0.0159 & 68.32 & 0.52 & \\
\hline
\end{tabular}

The plot (Fig.1) concentration versus \%IE shows that inhibitor efficiency is increased with increase in the concentration of the inhibitor for different immersion time 1day, 2 days, 3 days 4 days and 5 days.

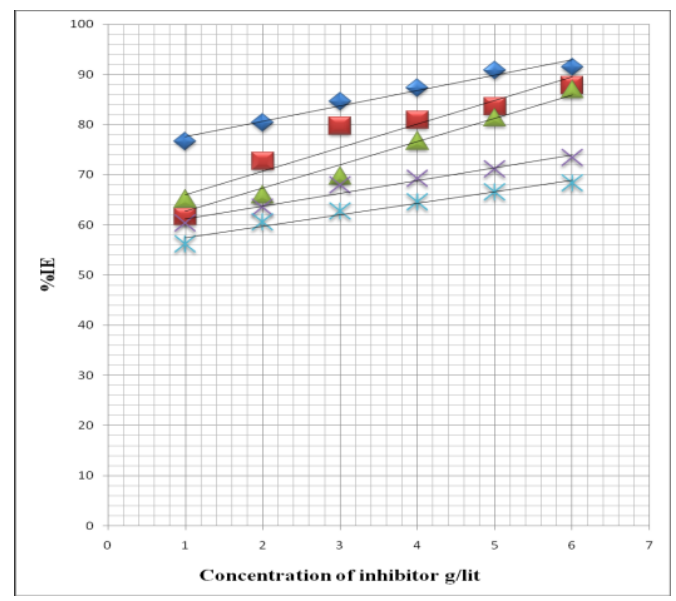

Figure 1: Variation of inhibition efficiency with concentration of inhibitor for iron in $0.5 \mathrm{~N} \mathrm{HCl}$ (immersion time: 1 day, 2days, 3days, 4days and 5 days).

Kinetics of iron corrosion in $\mathrm{HCl}$ solution with and without inhibitor:

Figures 2-3 show the dependence of $\log \mathrm{W}_{\mathrm{f}}$ (weight of iron at time $\mathrm{t}$ ) as a function of time. 


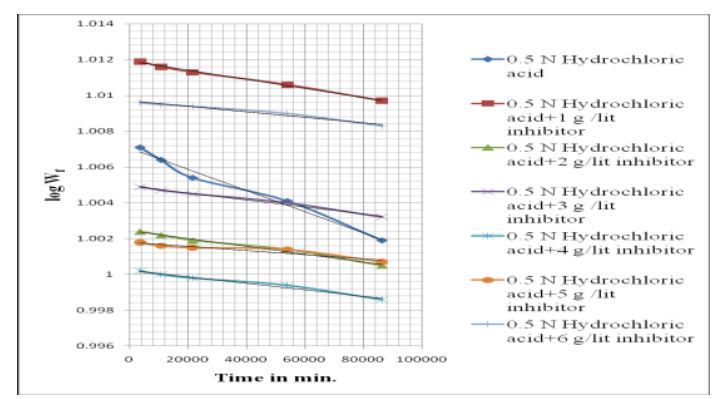

Figure 2: Kinetic plot for the corrosion of iron in $0.5 \mathrm{~N} \mathrm{HCl}$ with and without Clove oil as inhibitor.

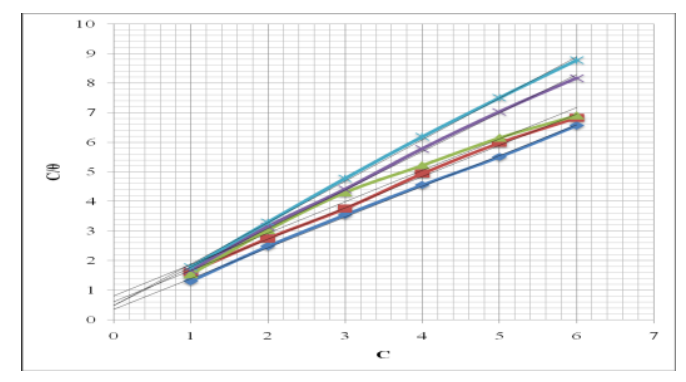

Figure 3: Langmuir adsorption isotherm for iron in $0.5 \mathrm{~N} \mathrm{HCl}$ with Clove oil for different immersion timings.

As seen in Figs.(2-3), the corrosion data fit in to the rate law for first order reaction as expressed in following equation.

$$
\log (\mathrm{Wi}-\Delta \mathrm{Wt})=(-\mathrm{k} / 2.303) \mathrm{t}+\log \mathrm{Wi}
$$

Where $\mathrm{k}$ is the first order rate constant, $\mathrm{W}_{\mathrm{i}}$ is the initial weight of iron sample, $\Delta \mathrm{W}_{\mathrm{t}}$ is the weight loss of iron sample at time $t$ and the term $\left(\mathrm{W}_{\mathrm{i}}-\Delta \mathrm{W}_{\mathrm{t}}\right)$ is the residual weight of iron sample at time $t$ and can designated as $\mathrm{W}_{\mathrm{f}}$ as shown in fig. 2.The obtained plots are linear which confirms first order kinetics for the corrosion of iron in $\mathrm{HCl}$ solution in the absence and presence of inhibitor. The values of rate constants obtained from the slope in figs. 2 are presented in Table 6 . The values of half life $t_{1 / 2}$ were calculated using the equation below [11].

$$
\mathrm{t}_{1 / 2}=0.693 / \mathrm{k}
$$

The rate constant $\mathrm{k}$ decreases with increase in concentration of inhibitor whereas half life increases with increasing concentration of the inhibitor. The increase in half life therefore supports the protection of the metal.

Table 6: Kinetic parameters for the corrosion of iron in varying concentration of Clove oil in $0.5 \mathrm{~N} \mathrm{HCl}$.

\begin{tabular}{|c|c|c|}
\hline Concentration of inhibitor(g/lit) & $\mathbf{K}\left(\mathbf{s}^{-1}\right)$ & $\mathbf{t}_{1 / 2}(\mathbf{s})$ \\
\hline 0 & $13.8 \times 10^{-7}$ & $5.02 \times 10^{5}$ \\
\hline 1 & $6.9 \times 10^{-8}$ & $1.0 \times 10^{7}$ \\
\hline 2 & $4.6 \times 10^{-8}$ & $1.50 \times 10^{7}$ \\
\hline 3 & $4.6 \times 10^{-8}$ & $1.50 \times 10^{7}$ \\
\hline 4 & $4.6 \times 10^{-8}$ & $3.0 \times 10^{7}$ \\
\hline 5 & $2.3 \times 10^{-8}$ & $3.0 \times 10^{7}$ \\
\hline 6 & $2.0 \times 10^{-}$ & \\
\hline
\end{tabular}




\section{Thermodynamic and adsorption consideration:}

The degrees of surface coverage $(\theta)$ for different inhibitor concentrations evaluated from weight loss method were tested graphically by fitting to various isotherms. The plot of $\mathrm{C} / \theta$ vs. C shows a straight line (Fig.3). This suggests that inhibitor covers both the anodic as well as cathodic regions through general adsorption following the Langmuir isotherm [12-13].

$$
\mathrm{C} / \theta=\mathrm{C}+1 / \mathrm{K}_{\mathrm{ad}}
$$

Where $\mathrm{K}_{\mathrm{ad}}$ is the equilibrium constant of adsorption. As the adsorption isotherm in $0.5 \mathrm{~N} \mathrm{HCl}$ is of Langmuir type with slope of almost unity, monolayer of the inhibitor species must have been attached to iron surface without lateral interaction between the adsorbed species. Values of free energy of adsorption $\Delta \mathrm{G}_{\mathrm{ads}}$ of Clove oil on iron surface were calculated using following equation [14].

$$
\Delta \mathrm{G}_{\mathrm{ads}}=-2.303 \mathrm{RT} \log (55.5 \mathrm{~K})
$$

Where $\mathrm{R}$ is gas constant, $\mathrm{T}$ is the temperature and $\mathrm{K}$ is the equilibrium constant of adsorption of clove oil on the surface of the iron and 55.5 is the concentration of water in the solution, value of $\Delta \mathrm{G}_{\mathrm{ads}}$ calculated from equation (7) are recorded in Table 7.

Table 7: Langmuir adsorption parameters for the adsorption of Clove oil on the surface of iron in $0.5 \mathrm{~N} \mathrm{HCl}$ for different immersion times.

\begin{tabular}{|c|c|c|c|c|}
\hline $\begin{array}{c}\text { Time } \\
\mathbf{1} \text { day }=\mathbf{2 4 h r s}\end{array}$ & $\mathbf{K}_{\text {ad }}$ & Slope & $-\Delta \mathbf{G}_{\text {ads }}$ & $\mathbf{R}^{2}$ \\
\hline $\mathbf{1}$ day & 2.84 & 1.039 & 26.13 & 0.998 \\
\hline 2 days & 1.62 & 1.056 & 19.16 & 0.998 \\
\hline 3 days & 1.23 & 1.059 & 16.989 & 0.983 \\
\hline 4 days & 2.84 & 1.302 & 26.13 & 0.998 \\
\hline 5 days & 2.057 & 1.401 & 21.66 & 0.998 \\
\hline
\end{tabular}

The negative values of $\Delta \mathrm{G}_{\text {ads }}$ indicate spontaneous adsorption process and stability of the adsorbed layer on the metal surface. Literature review reveals that with regard to energetic adsorption process, two types of adsorption processes had been established [15-16]. Physisorption (electrostatic interaction between the charged molecules and charged metal) in which the $\Delta \mathrm{G}_{\mathrm{ads}}$ is up to $-20 \mathrm{kJmol}^{-1}$ and chemisorption (charge sharing or transfer from the inhibitor molecules to the metal surface to form co-ordinate bond) where the $\Delta \mathrm{G}_{\text {ads }}$ is more negative than $-40 \mathrm{~kJ}$ mol-1. The $\Delta \mathrm{G}_{\mathrm{ads}}$ value (Table 7) supports the mechanism of physisorption for the adsorbate on the iron surface. This negative value is indicating spontaneous adsorption of the inhibitor on the surface of iron.

Scanning electron microscope (SEM), investigations also indicate that clove oil greatly lowers the dissolution currents. The SEM images shown in figures $(4-6)$ provide an explanation for the phenomena.

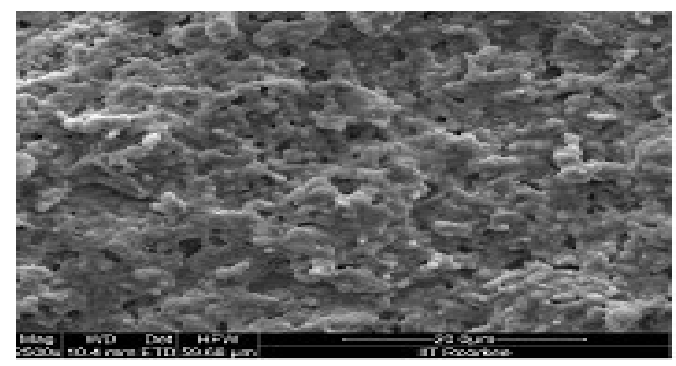

Figure 4: SEM Image of iron in $0.5 \mathrm{~N} \mathrm{HCl}$ without inhibitor. 


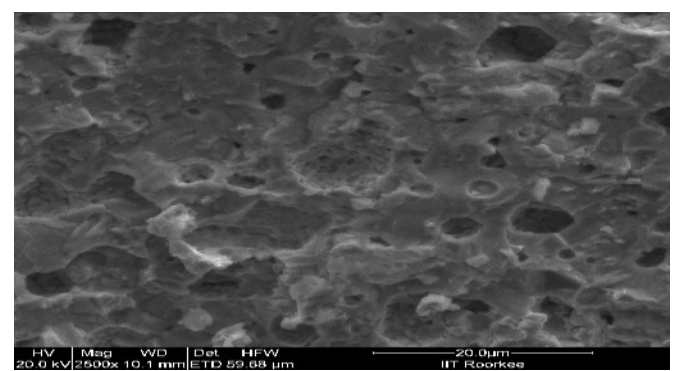

Figure 5: SEM Image of iron in $0.5 \mathrm{~N} \mathrm{HCl}$ with inhibitor $1 \mathrm{~g} /$ lit.

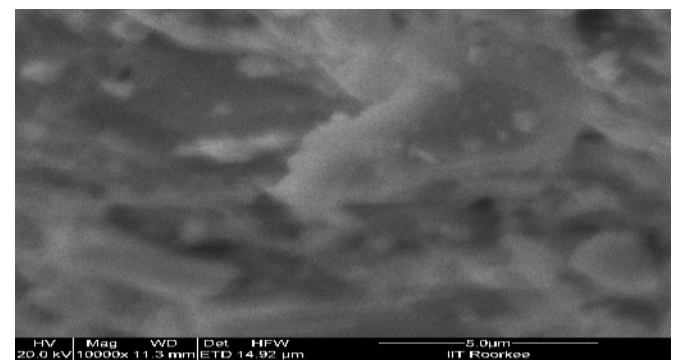

Figure 6: SEM Image of iron in $0.5 \mathrm{~N} \mathrm{HCl}$ with inhibitor $3 \mathrm{~g} /$ lit.

From the SEM images It is clear that the plate of iron is uniformly covered with the protecting film. This observation clearly proved that the inhibition is due to the formation of an insoluble barrier film on the iron surface.

\section{Conclusion}

Clove oil acts as an excellent corrosion inhibitor in $0.5 \mathrm{~N} \mathrm{HCl}$ solution. The inhibition efficiencies of almost $98 \%$ in $0.5 \mathrm{~N} \mathrm{HCl}$ have been obtained with small amount of Clove oil $(5 \mathrm{~g} / \mathrm{lit} . \mathrm{HCl})$ by weight loss technique at room temperature.

\section{References}

1. Bentiss F, Lebrini M, Lagrenee M, Corros. Sci. 2005, 47, 2915.

2. Bouklah M, Aouniti A, Hammouti B, Benkaddour M, Lagrenee M, Bentiss F, Prog. Org. Coat., 2004, 51, 118.

3. Wang H, Liu R, Xin J, Corros. Sci., 2004, 46, 2455.

4. Chetouani A, Hammouti B, Aouniti A, Benchat N, Benhadda T, Prog. Org. Coat., 2002, 45, 373.

5. Morad M S, Mater. Chem. Phys., 1999, 60,188.

6. Ouchrif A, Yahi A, Hammouti B, Dafali A, Benkaddour M, Touhami E, Bull. Electrochem., 2003, 19, 445.

7. Dhayabaran V, Rajendran A, Vimala J R, Anandhakumar A, Trans. SAEST, 2005, 40, 134.

8. Subramania A, Sundaram N T K, PriyaR S, Muralidharan V S, Vasudevan T, Bull. Electrochem., 2004, 20, 49.

9. Okorosaye K O, Oforka N C, J. Appl. Sci. Environ., 2004, 8, 57.

10. Atkins P W, "Chemisorbed and Physisorbed Species", A Textbook of Physical Chemistry; University Press: Oxford, 1980.

11. Chandrasekaran V, Khannan K, Bull. Electrochem., 2004, 20, 471. 
12. Langmuir I, J. Amer. Chem. Soc., 1947, 39, 1848.

13. Quraishi M A, Mideen A S, Khan M A W, Ajmal M, Indian J. Chem.Technol., 1994, 1, 329.

14. Schorr M, Yahalom Y, Corros. Sci., 1972, 12, 867.

15. Abiola O K, Oforka N C, Mater. Chem. Phys., 2004, 83, 315.

16. Abiola O K, J. Chil. Chem. Soc., 2005, 50, 597. 


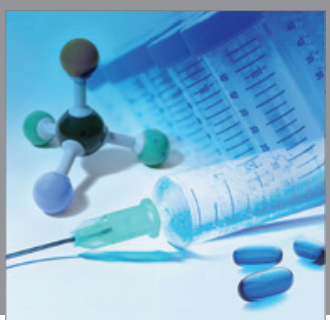

International Journal of

Medicinal Chemistry

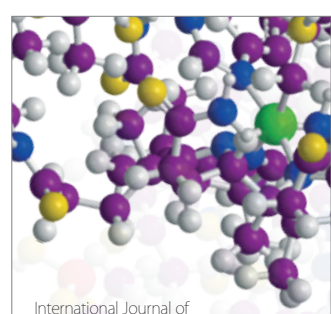

Carbohydrate Chemistry

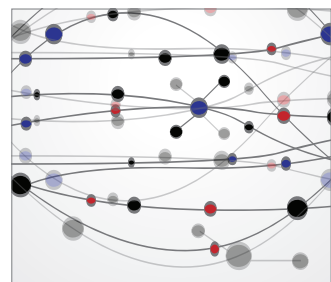

The Scientific World Journal
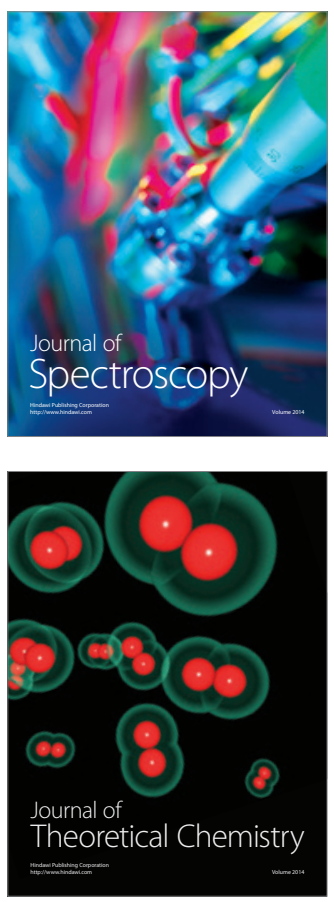
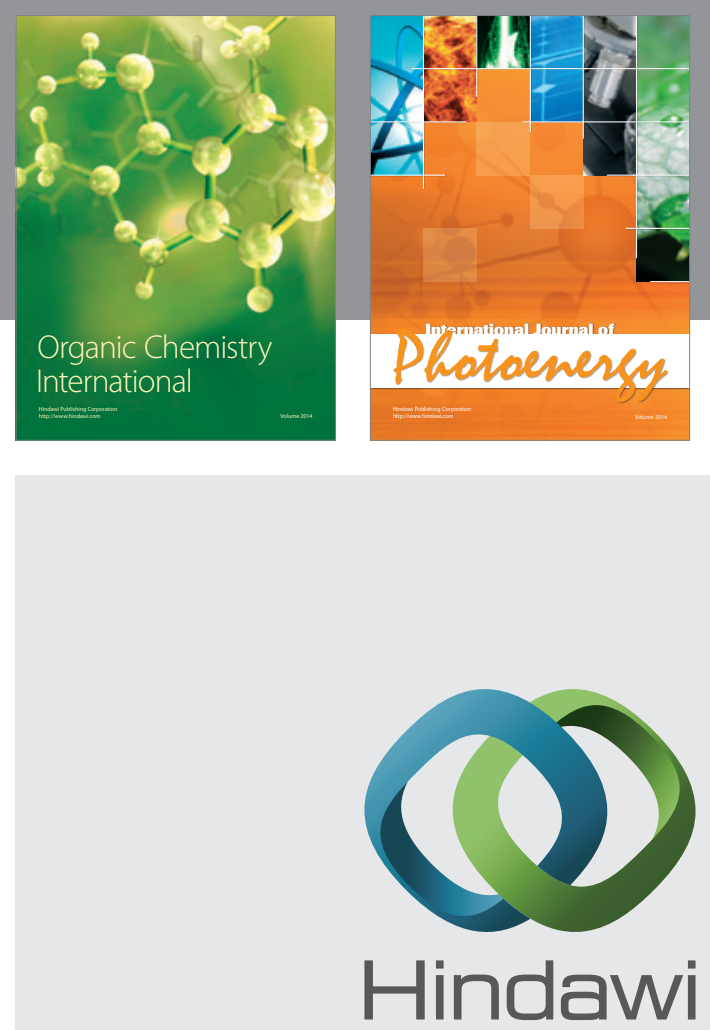

Submit your manuscripts at

http://www.hindawi.com
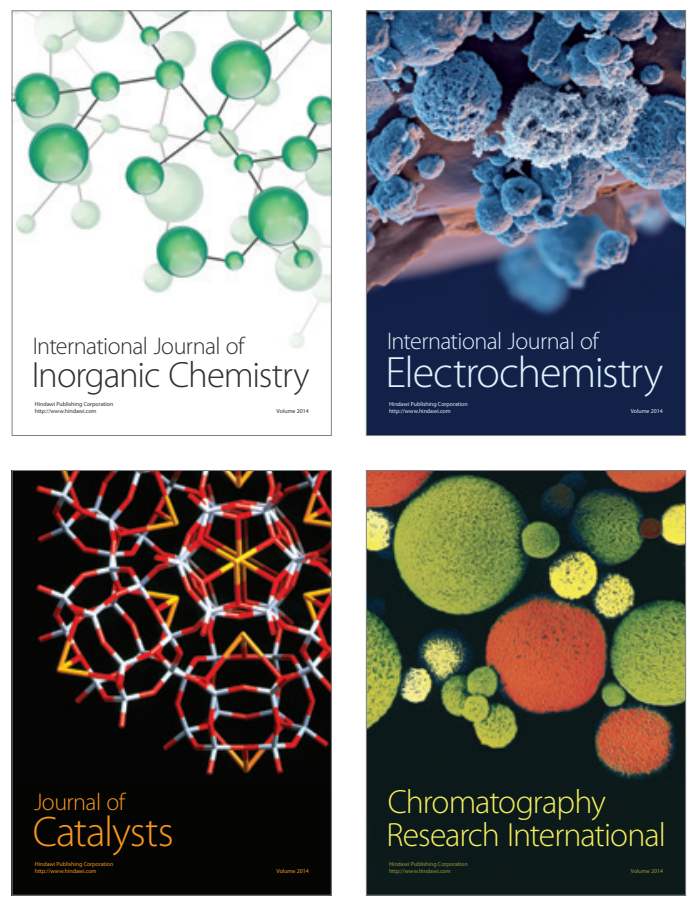
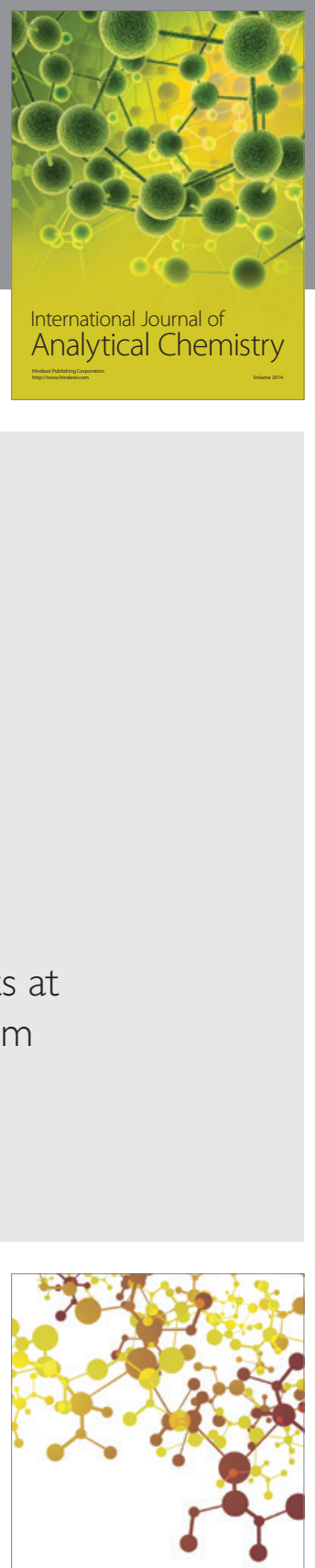

Journal of

Applied Chemistry
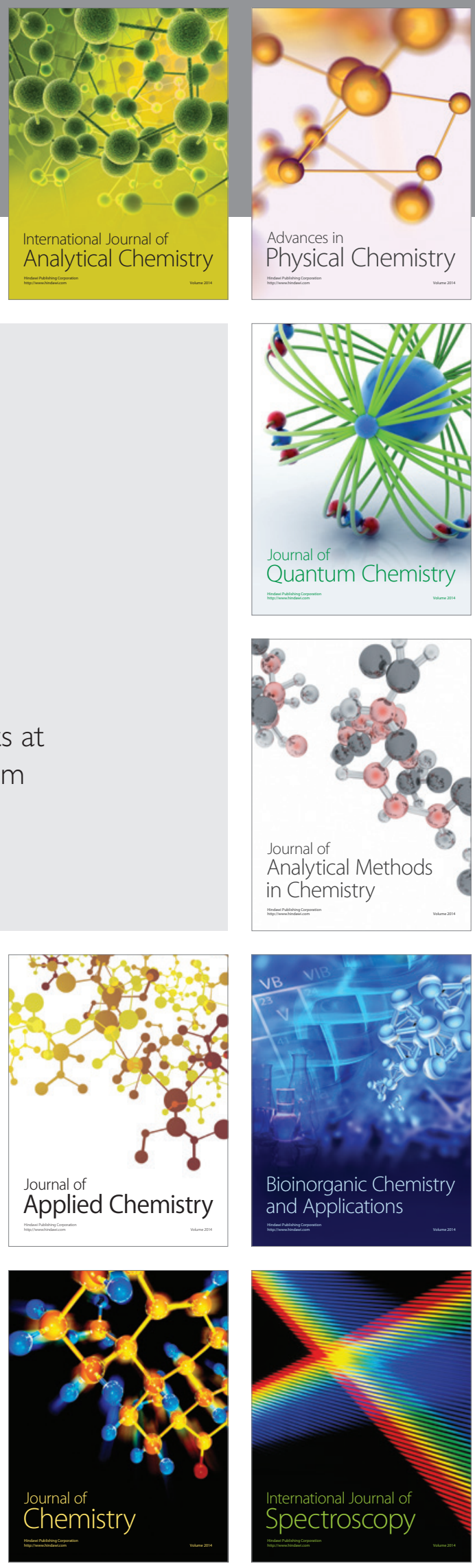